\title{
The effects of organizational structure on the entrepreneurial orientation of the employees
}

\author{
Behzad Shoghi \\ Islamic Azad University, Iran \\ bsh417@ymail.com \\ Aboulfazl Safieepoor \\ Islamic Azad University, Iran \\ asp562002@yahoo.com
}

\begin{abstract}
This study aims to investigate the effects of organizational structure on the entrepreneurial orientation of the employees in metal industries of Kaveh Industrial City of Iran. The research was conducted in 2012. The methodology of this research is functional according to its objective, and it is a descriptive survey according to its data collection method, and it is a quantitative research due to the type of its data that have been collected by questionnaire. In order to assess the dimensions of the organizational structure we have used Robin's Standard Questionnaire and in order to measure the entrepreneurial orientations, we have used Dess and Lumpkin's standard questionnaire of entrepreneurial orientation. The pollution of the research was included 4700 employee involved in metal industries of Kavek Industrial City, among whom, 355 people was selected as the research sample by using Cochran formula and sampling method of relational stratified random sampling method. Then we applied Spearman's regression test and multi-regression (in SPSS) and the Structural Equation Modeling (in LISREL) to analyze the data. The analysis showed that the organizational structure has a positive significant effect on the entrepreneurial orientation of the employees of the organization. The finding of this research can help the managers of the metal industry identify the weaknesses and strengths of their organizational structure and the appearance of people's orientations and behaviors toward the entrepreneurial activities.
\end{abstract}

Keywords: Organizational structure, Formalization, Complexity, Centralization, Entrepreneurial orientation, Metal industries.

JEL classification: L22, M51. 


\section{INTRODUCTION}

In recent years, the increasing competition and the instability of the environmental conditions has led to new situations in which the big organizations that have not changed their methods and structures fail to compete the small organizations that are more flexible and more innovative. The organizations that encourage the entrepreneurship and nurture the talents of the people are very valuable for the society. Nowadays, the organizations are increasingly placed in situations in which it is necessary to tend toward the entrepreneurial activities (Shepherd, et al., 2008). The organizations have to meet the conditions in which the spirit of entrepreneurship governs the whole organization, and the employees can approach the entrepreneurial activities whether individually or in group. This is why different organizations willingly promote the entrepreneurial activities among their employees. One of the most important factors that facilitate the entrepreneurship in organizations is the suitable organizational structure that is appropriate to the goals of that organization. Any organization that intends to do entrepreneurial activities must adopt a flexible and entrepreneurial structure. The suitable conditions for the entrepreneurial activities cannot be created without the needed backings, but the organizational structure has to make the grounds for appearance of such backings (Johnson and Van de Ven, 2002). Thus the identification of such factors plays an important role in creating such an entrepreneurial space and reinforces the flows of creativity and innovation in organization. The main problem of this research deals with the effects of the different dimensions of organizational structure on the entrepreneurial orientations of the employees in organization, and to specify the relationship between these dimensions to understand the ways of conducting people's orientations and tendencies toward the entrepreneurial activities and to improve the organizational entrepreneurship.

\section{THEORETICAL FOUNDATIONS OF THE RESEARCH}

\subsection{Organizational structure}

The studies on the successful organizations show that one of the most effective factors on the establishment of different dimensions of entrepreneurial orientation in organizations is the organizational structures of those organizations. Mintzberg (1972) defines the organizational structure as follows: organizational structure can be defined as a set of methods that separate the tasks of the individuals in different sections and then coordinate those tasks (Willem and Buelens, 2009). Organizations have different types of structures that are used based on the needs and conditions of each organization. In a general classification, there are two types of structures: mechanical and organic. Mechanical structure is used for stable and predictable environments and organic structures are used for turbulent and instable environments (Gresov and Drazin, 2007). Mechanical structure of the organization is known by some characteristics like the complexity, centralization, formalization, and planned behaviors in form of the rules and regulations (Mihm et al., 2010). On the other hand, organic organizational structure is flexible and is known by some characteristics like decentralized authorities, less rules and regulations, and less formal communications (March and Simon, 2009).

Based on the available definitions in the literature about the structural dimensions of the organization, it is too hard to specify a set of dimensions for the structural organization without having a specific framework and specific goals (Morton and Hu, 2008). Accordingly, referring to the proposed hypotheses of this research, Robbins's research (1998) on the dimensions of the structure (including three dimensions of complexity, formalization and centralization) has been selected as our criteria for studying the organizational structure due to its scientific backings. 
a) Complexity: According to Daft, complexity is the number of the management levels that exist in the organization (Daft, 2006). Generally, complexity refers to the number of job titles (inter-organizational job distribution), number of the hierarchy and management levels, educational levels, and geographical distribution of the departments and branches of the organization. complexity is divided to two classes: vertical complexity and geographical complexity (Gresov and Drazin, 2007);

b) Formalization: formalization refers to the scale of using rules and regulations for describing the behaviors (Liao, et al, 2010). Generally, formalization is the scale of defining the rules, regulations, instructions, provisions, job descriptions that are part of the organization (Gresov and Drazin, 2007);

c) Centralization: The third dimension of the organizational structure is the centralization. Most researchers agree that the centralization refers to the concentration of the power of decision making at the top levels of the management in organization (Wilm and Bones, 2009; Liao, et al, 2010; Child, 2008). More centralization can integrate the policies of the organization and reduces the risks of the employees at the lower levels of the organization who have less information or skills (Katsikea et al, 2011).

\subsection{Entrepreneurial orientation}

In today's dynamic competitive environments and global rapid changes, the organizations are increasingly committed to do entrepreneurial activities in order to survive and gain competitive successes (Covin and Kuratko, 2008). Nowadays, entrepreneurship is considered as an important tool for the development because the entrepreneurial persons can create the grounds of the successfulness. Naman and Slowin (1993) believe that in turbulent and instable environments the companies are more willing to be innovative, risktaker, and pioneer. An entrepreneurial organization is always able to adjust itself with the changes occurring in its external environment and makes its programs compatible with the environmental changes. The idea of organization entrepreneurship is a subject in the global economy the managers must not only be familiar with it, but they have to understand and implement it in their organization. In order to be successful, the organizations have to have a vision that promotes and encourages the innovation and risk-taking so that they can be adapted to the ever-changing global economy. Organizational entrepreneurship refers to the innovated products or processes that are emerged through creating the entrepreneurial culture in a pre-established organization (Hornsbey et al., 1993). The organizations that wish to conduct the organizational entrepreneurship successfully will need an entrepreneurial orientation. Entrepreneurial orientation refers back to the activities of determining the strategies that the businesses use to identify and conduct new-emerging companies. Entrepreneurial orientation offers a mental framework and a perspective on the entrepreneurship that is mirrored in the current process of the company and the organizational culture of that company. Most researchers believe that if the organizations have a strong entrepreneurial orientation they would meet their goals more efficiently (Dass and Lumpkin, 2005; Chen, et al, 2006; Naldi, et al, 2007). In other words, entrepreneurial orientation includes the intentions and activities of the key actors in the process of dynamic productions in light of the new-emerged opportunities. Covin and Slowin (1989) suggest that the entrepreneurial orientation is a multi-dimensional construct and it can be evaluated from different points of view (Chang, et al. 2007). For example, Miller (1983) suggests specific dimensions for describing entrepreneurial orientation. He introduces entrepreneurial company as a company dealing with the markets with innovative products, having low risks, being pioneer in market, and pressuring the competitors. Innovation is the scale of the willingness of the companies to approach the new ideas and creative processes whose results may be emerged in new products, services, and/or technological processes. Innovation requires separating the company from its current technologies and moving beyond its current situation (Chadwick, et al, 2008). Risk-taking implies the willingness of the companies to assign its main resources to the projects that may or 
may not being successful and thus it is possible for these projects to fail. Moreover, risk-taking refers to the rapid following-up of the opportunities, rapid supply of the resources, and courageous activities (Chang, et al, 2007). Pioneer organizations supervise the market procedures, detect the future needs of the customers, and predict changes in demands or any problems that can lead to new opportunities for the company.

Lumpkin and Dess (1996) added to further factors that can play important role in the entrepreneurial orientation: aggressive approach and autonomy. Aggressive approach refers to the willingness of the company to be involved in direct and hard challenge with the competitors in order to improve the situation of its own market. The companies that try to build their competitive position aggressively and use the opportunities forcefully to benefit can preserve their competitive advantage in long term if their goal is to succeed the competitors and not to damage them (Dess and Lumpkin, 2005). Autonomy refers to the independent activities of the individuals or groups in order to come to new ideas and their implementation. In other words, organizational actors follow self-controlling opportunities, independent activities, making key decisions and implementing new ideas independently (Chang, et al, 2007). Generally, the characteristics of entrepreneurial orientation can be generalized to the styles of decision-making and the activities of the members of an organization. These factors (including innovation, risk-taking, pioneering, aggressive approach and autonomy) usually work together to improve the entrepreneurial performance of the organization.

The literature review shows that the organizational structure has an affects the entrepreneurial orientation of the employees. Among the most important studies in the mentioned literature we can refer to the followings:

Yao, et al. (2009) have introduced organizational factors such as the organizational structure, organizational strategy, and organizational culture as the important and effective factors on the performance. Moreover, Lumpkin, et al, (2010) believe that autonomy is the most important factor among the dimensions of the entrepreneurial orientation. They found that the autonomy is the most effective factor on the performance of the organization. Besides, Katsikea, et al, (2011) point to the positive effects of the formalization and centralization on the occupational feedbacks of the employees and add that the centralization has a negative relationship with job independence and job diversity.

Focusing on the both mentioned main constructs, the hypotheses of this research are proposed as follow:

Main hypothesis (Ha): the structure of an organization is effective on the appearance of the entrepreneurial orientations of the employees of metal industries.

Subsidiary hypothesis 1 (Hb1): the scale of the complexity of organization is effective on the entrepreneurial orientation of the employees of metal industries.

Subsidiary hypothesis 2 ( $\mathrm{Hb} 2)$ : the scale of the formalization of organization is effective on the entrepreneurial orientation of the employees of metal industries.

Subsidiary hypothesis 3 ( $\mathrm{Hb} 3$ ): the scale of the centralization of the decision-makings in organization is effective on the entrepreneurial orientation of the employees of metal industries.

\section{THEORETICAL FRAMEWORK OF THE RESEARCH}

Considering the main objective of this research that is to study the role f organizational structure on the entrepreneurial orientation of the employees of metal industries, and considering the hypotheses of the research, the theoretical framework of the research is presented in figure 1. 


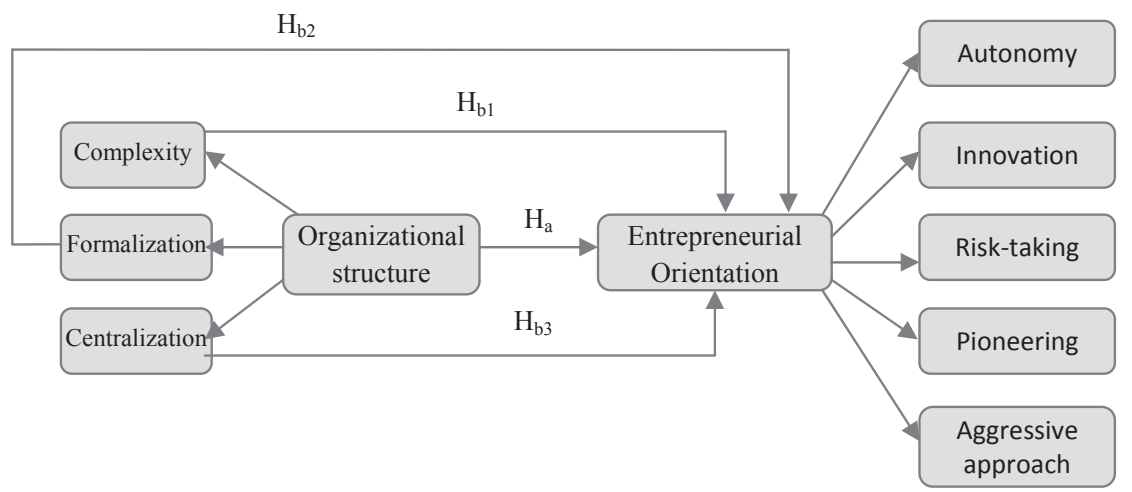

Figure 1: Theoretical framework of the research

\section{METHODOLOGY OF THE RESEARCH}

Since in this research a causal relationship is supposed to be studied, the methodology of the research is causal according to the relationship between the variables, while we have used structural equation model to come to a inclusive study of the conceptual model of the research. Structural equation model is the best tool for the researches in which the observed variables have measuring errors, and the relationship between their variables is complex. Using this method we can study the indexes or observed variables on one hand and to assess the causal relationship between the latent variables and the explained value of variance (Hair and et al., 2010). Structural equation model encompasses two models: measurement model and the structural model; and the variables of the model are divided into two groups: latent variables and observed variables. In this research, organizational structure and entrepreneurial orientation are the latent variables, and formalization, complexity and centralization are observed variables that are considered as the indexes of the organizational structure. On the other hand, innovation, risk-taking, autonomy, pioneering and aggressive approach are observed variables that are considered as the criteria for measuring the entrepreneurial orientation.

\subsection{Statistical population, sampling method, and sample size}

The population of the research contains all employees in the companies of metal industry in the Iranian Kaveh Industrial City, which includes 4700 employees. The companies of the metal industry in the Iranian Kaveh Industrial City (36 companies) were divided into 4 groups: aluminum metal manufacturing companies, non-aluminum metal companies, household appliances, and automobile.

Relying on the relative stratified random sampling method, 12 companies out of the 36 active companies in the metal industry were selected as the sample. Then using the Cochran formula, we specified the sample size for our 4500 subject population. To use the Cochran formula it is necessary to consider its assumptions. The assumptions of the Cochran formula include: $\mathrm{p}=\mathrm{q}=50 \%$ (on the basis of probabilistic method); $\mathrm{z}$ is the standard statistic for normal distribution that is equal to 1.96 at the confidence level of $95 \%$; $\mathrm{d}$ is the maximum allowable error (equal to $5 \%$ for this research); and $\mathrm{N}$ is the number of the employees in all relevant companies. The sample size (n) is calculated according to equation 1 on the basis of the Cochran formula (Saraei, 2000): 


$$
\mathrm{n}=\frac{\mathrm{z}^{2} \mathrm{pqN}}{\mathrm{Nd}^{2}+\mathrm{z}^{2} \mathrm{pq}}
$$

Thus using the equation 1, considering the number of the statistical population (4700), 355 subjects were selected as the statistical sample. At the last step, regarding the number of the employees of each company and the total sample, we calculated the sample of each company separately. It is to be mentioned that 370 questionnaires were distributed among which the number of 360 questionnaire were completed and got back (response rate of 97\%), and 5 questionnaires were removed due to their incompleteness. Thus the statistical operation was conducted on 355 subjects.

\subsection{Data collection instrument; reliability and validity}

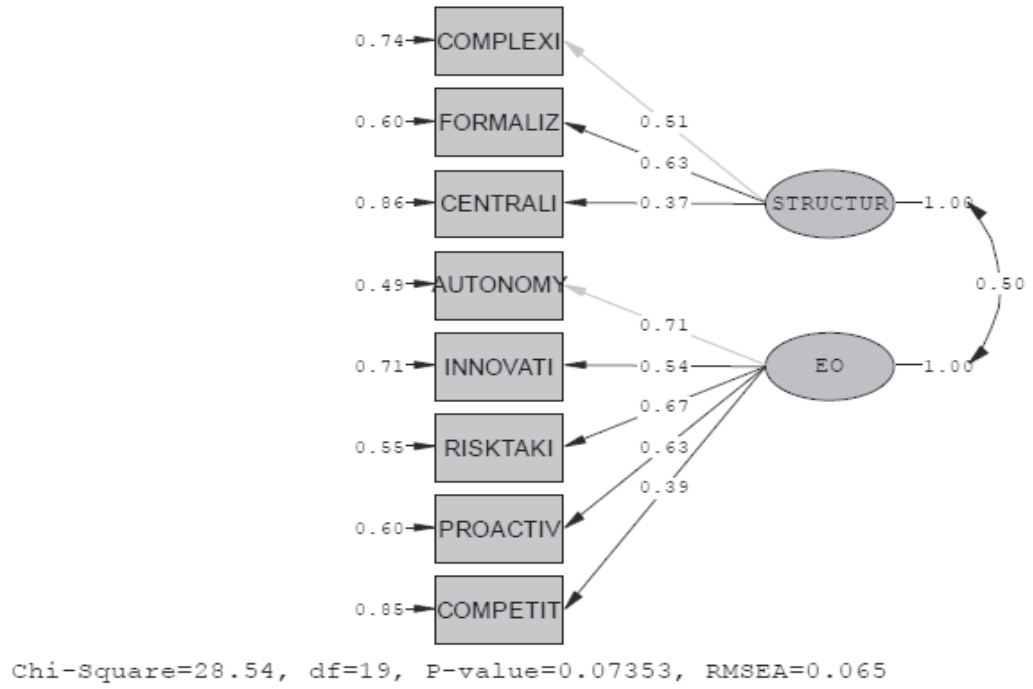

Figure 2: Measurement models for the two constructs

In order to collect the needed data of the research, we used Robbins's standard questionnaire (1998) for measuring the organizational structure, and we have used Dess and Lumpkin's standard questionnaire of entrepreneurial orientation (2005: 153) for measuring the entrepreneurial orientation. The formal validity of the questionnaire was tested through collecting the opinions of the experts (some professors of the University of Tehran) and the needed corrections ware applied on the questionnaire. On the other hand, to evaluate the reliability of the questionnaire we used Cronbach's alpha method, and the Cronbach's alpha coefficient for each of the dimensions was obtained as follow: complexity: 0.79 ; formalization: 0.82 ; centralization: 0.77 ; innovation: 0.80; risk-taking: 0.72; autonomy: 0.76; pioneering: 0.77 ; and aggressive approach: 0.81 . Since all coefficients are higher than 0.7 , thus the measurement instrument of the research is reliable (Nunnally, 1978). After collect- 
ing the questionnaires, we first conducted exploratory factor loading using SPSS 20. Since all extracted values in the communalities table were higher than 0.5 , thus no one of the factors was removed from the analysis. At the next step, we conducted confirmatory factor analysis using LISREL 8.8 in order to assess the used measuring model. The fitness conditions of the model are as follow: the significant level obtaining from the chi-square test (p-value) is higher than 0.05 ; the ratio of chi-square to degree of freedom is less than 3 ; the value of the statistic of Root Mean Square Error of Approximation (RMSA) is less than 0.05; the value of comparative fitness index (CFI), general fitness index (GFI), adjusted general fitness index (AGFI), and non-norm fitness index (NNFI) are higher than 0.9 (Joreskog and Sorbom, 1996). As shown in figure 2, p-value is equal to 0.073, RMSA statistic is equal to 0.065 , and the ratio of chi-square to degree of freedom less than 3 .

Moreover, other outputs of LISREL showed that the value of CFI is equal to 0.943 , the evaluated value of $\mathrm{Z}$ is higher than 1.96; and the values of GFI and AGFI are equal to 0.927 and 0.911 respectively. Thus the measurement models of the two main constructs of the research have an acceptable fitness.

\section{Data analysis}

Since the correlation coefficient is the base for determining the precision of the regression estimation, thus these two techniques have to be used together. In order to test the hypotheses we first used the Spearman's Correlation test (to determine the direction and intensity of the relationship between the variables) and multi-regression (to predict the changes in dependant variable by the independent variables) using SPSS 20; then the causal relationship between the dependant variable and the independent variables as tested in LISREL 8.8 in the form of structural equation model. Tables 1 and 2 show the results of correlation and regression tests respectively.

Table 1

Correlation matrix between the main constructs of the research

\begin{tabular}{|l|c|c|c|}
\hline \multicolumn{1}{|c|}{ Constructs } & Organizational structure & $\begin{array}{c}\text { Entrepreneurial } \\
\text { orientation }\end{array}$ & Significance level \\
\hline Organizational structure & -0.751 & 1 & 0.000 \\
\hline Entrepreneurial orientation & 1 & -0.751 & 0.000 \\
\hline
\end{tabular}

Source: own calculation.

Table 2

Matrix of regression coefficients

\begin{tabular}{|l|c|c|c|}
\hline & Significance level & t-values & Beta standardized values \\
\hline Fixed value & 0.001 & 3.553 & -0.561 \\
\hline Complexity & 0.000 & $-44-911$ & -0.343 \\
\hline Formalization & 0.000 & -7.112 & -0.143 \\
\hline Centralization & 0.000 & -6.332 & \\
\hline
\end{tabular}

Source: own calculation.

Since in the regression and correlation matrixes the level of significance is less than the error value (0.05), thus we can claim at $95 \%$ confidence level that the relationship between organizational structure 
(and its dimensions) and the entrepreneurial orientation is significant. Moreover, the negative sign of the coefficients show implies the inverse relationship between the two constructs, and the beta coefficients show that $56 \%$ of the changes in entrepreneurial orientations is predicted by complexity, $34 \%$ of it is predicted by formalization, and $14 \%$ is predicted by the centralization.

At the next step, we assessed the causal relationship between the organizational structure (and its dimensions) and the entrepreneurial orientation in structural model. As shown in figure 3, all mentioned suitability conditions of the fitness model are true here. Moreover, the relationship between the organizational structure and the entrepreneurial orientation is significant and inverse; i.e. the organizational structure has a negative effect on the entrepreneurial orientation. This point will be illustrated in the conclusion section in more details.

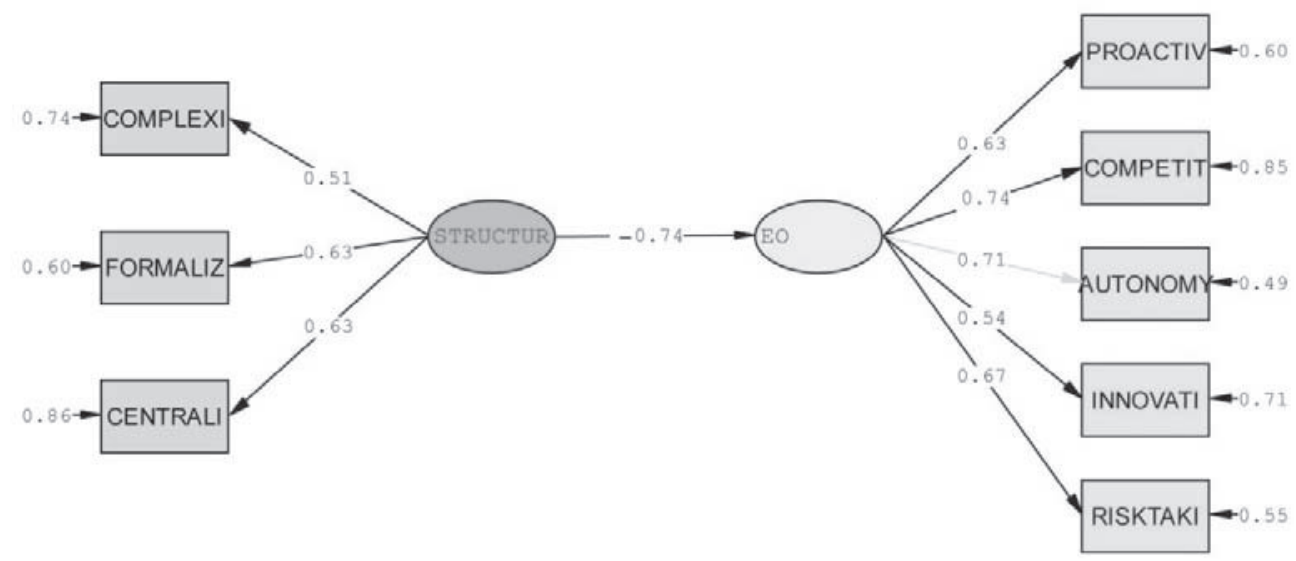

Chi-Square $=35.74, d f=19, \quad P-v a l u e=0.07136, \quad$ RMSEA $=0.077$

Figure 3: structural equation model (standardized coefficients)

LISREL output confirms the main and subsidiary hypotheses of the research, as shown in table 4. Since all t-values are significant, thus all hypotheses are confirmed.

Table 4

Testing the hypotheses of the research

\begin{tabular}{|l|c|c|c|}
\hline \multicolumn{1}{|c|}{ Hypotheses } & $\begin{array}{c}\text { Standardized } \\
\text { coefficients }\end{array}$ & t-value & Result \\
\hline Organizational structure $\rightarrow$ Entrepreneurial orientation & -0.74 & -16.71 & confirmed \\
\hline$\chi 2=35.74 \mathrm{df}=19$ RMSEA $=0.077$ GFI $=0.93$ AGFI $=0.91$ & -0.82 & -18.72 & confirmed \\
\hline Complexity $\rightarrow$ Entrepreneurial orientation & -0.82 & -18.72 & confirmed \\
\hline Formalization $\rightarrow$ Entrepreneurial orientation & -0.87 & -19.87 & confirmed \\
\hline Centralization $\rightarrow$ Entrepreneurial orientation & \multicolumn{3}{|l}{} \\
\hline \multicolumn{2}{|l|}{$\chi^{2}=44.21 \quad \mathrm{df}=18 \quad$ RMSEA $=0.061 \quad$ GFI=0.94 } & AGFI $=0.92$ \\
\hline
\end{tabular}

Source: own calculation. 


\section{DISCUSSION AND CONCLUSION}

As pointed out in the theoretical foundations of the research, the experts of different fields believe that the entrepreneurial activities of the employees in organization have a considerable effect on the successfulness of that organization. Many researches show that different factors play role in the appearance of the entrepreneurial orientations of employees, among which one can refer to the resources of the organization, management of the organization, organizational structure, and organizational culture (e.g. Yao, et al, 2009; Learner and Shaker, 2007; Caruana, et al, 2002). In the main hypothesis of the research we found that the structure of the organization affects the entrepreneurial orientation of the employees. In this regard, the results of Jogartnam, et al (2006) showed that organic structure of the organizations can lead to the increase of innovative activities of the employees considerably. Moreover, Zahra and Covin (1995) stated that the organizational structure is one of the factors that play a decisive role in the organizational entrepreneurship. Thus our findings are consistent with the findings of the mentioned researches. Besides, on the subject of the complexity, Learner and Shaker (2007) have stated that the lack of complexity of the organizational structure and the consistency of the structure with the organizational criteria will lead to the improvement of the organizational entrepreneurship. Strict and rigorous rules and regulations in the organization is a factor that decreases the entrepreneurial orientation of the employees in organization. Evangelia, et al, (2011) have concluded that the formalization is a factor that has a negative effect on the job independence and job diversity. Since the autonomy is one of the dimensions of entrepreneurial orientation, the mentioned research confirms the effect of the formalization on the entrepreneurial orientation of the employees of organization. In yet another research, Caruana, et al, (2002) found that in the organizations with decentralized systems, higher levels of creative ideas will be produced. And finally, Lumpkin, et al, (2010) have stated that the autonomy has a direct relationship with the centralization and it is the most important and most effective dimension of the entrepreneurial orientation that leads to the improvement of the organizational performance. The findings of our research confirm they results.

\section{SUGGESTIONS}

Considering the confirmation of the main hypothesis of the research, we suggest that the managers of metal industries reduce the scale of the formalization and complexity of the organizational structure on one hand, and make the employees participate in the decisions of the organization on the other hand to make them ready to nurture their entrepreneurial orientation. Additionally, for the next researches we suggest the researchers to focus on the other factors like the organizational culture, management styles, and other factors that affect the entrepreneurial orientation. Moreover, the researchers can study the barriers that make trouble for the establishment of new businesses from both individual and organizational points of view and study each of these organizational factors on the different types of individual factors one of which is the entrepreneurial orientation of the people. Next studies can investigate the factors that play a mediating role in the relationship between the organizational structure and the entrepreneurial orientation, as Lumpkin and Dess (1996) had suggested to study the mediating variables in the relationship between the entrepreneurial orientation and the organizational performance (including the environmental variables and the organizational variables). 


\section{REFERENCES}

Caruana, A., Ewing, M. T., \& Ramaseshan, B. (2002), Effects of some environmental challenges and centralization on the entrepreneurial orientation and performance of public sector entities, The Service Industries Journal, 22(2), pp. 43-58.

Chadwick, Ken; Barnett, Tim; Dwyer, Sean (2008), An Empirical Analysis of the Entrepreneurial Orientation Scale, Journal of Applied Management and Entrepreneurship, Vol. 13, No.4, pp. 64-85.

Chang, sh; Lin, R; Chang, F; Chen; R. (2007), Achieving manufacturing flexibility through entrepreneurial orientation, Industrial Management \& Data Systems, Vol. 107, No. 7.

Chen, J.C.H., Parker, L.J. and Lin, B. (2006), Technopreneurship in native American businesses: current issues and future with a case study, International Journal of Management and Enterprise Development, Vol. 3, No 1/2, p. 7084.

Child. J, (2008), Organization structure, environment, and performance: the role of strategic choice, Sociology, V 6, pp. $1-22$.

Covin, J. G., \& Kuratko, D. F. (2008), The concept of corporate entrepreneurship. in V. Narayanan \& G. O'Connor (Eds.), The Blackwell encyclopedia of technology and innovation management, Oxford, UK: Blackwell Publishers.

Daft, R. 1. (2006), The new era of management, india edition, Thomson, south estern.

Dess, G.G. and Lumpkin, G.T. (2005), The role of entrepreneurial orientation in stimulating effective corporate entrepreneurship, Academy of Management Executive, Vol. 19, No. 1, pp. 147-156.

Furst, R. M. (2005), An exploration of corporate entrepreneurship: Venturing signatures and their underlying dynamics, From www. Wilkes.Edu/Include/Academics/Gradbulletin_0304.Pdf

Garcia-Morales, V.J., Llorens-Montes, F.J. and Verdu-Jover, A.J. (2006), Antecedents and consequences of organizational innovation and organizational learning in entrepreneurship, Industry Management \& Data Systems, Vol. 106, No. 1, pp. 21-42.

Gresov, C. and Drazin, R. (2007), Equifinality: functional equivalence in organization design, Academy of management review, Vol. 22, pp. 403-428.

Hair, J. F., Black, W. C., Babin, B. J., Anderson, R. E., \& Tatham, R. L. (2006), Multivariate data analysis, Englewood Cliff, NJ: Pearson Prentice Hall.

Hornsby, J. S., Kuratko, D. F., \& Zahra, S. A. (2002), Middle managers' perception of the internal environment for corporate entrepreneurship: Assessing a measurement scale, Journal of Business Venturing, 17(3), pp. 253-273.

Jogaratnam, G. \& Ching-Yick Tse, E. (2006), Entrepreneurial orientation and the structuring of organizations, International Journal of Contemporary Hospitality Management, 18(6), pp. 454-468.

Johnson, S. \& Van de Ven, A.H. (2002), A framework for entrepreneurial strategy. in M.A. Hitt, R.D. Ireland, S.M. Camp, \& D.L. Sexton (Eds.), Strategic entrepreneurship: Creating a new mindset (pp.66-85). Oxford,UK.: Blackwell Publishers.

Jöreskog, K. \& Sörbom, D. (1996), Structural Equation Modeling with the SIMPLIS Command Language, Chicago, IL: Scientific Software International, Inc.

Katsikea, E; Theodosiou, M; Perdikis, N; Kehagias, J. (2011), The effects of organizational structure and job characteristics on export sales managers' job satisfaction and organizational commitment, Journal of World Business, Vol. 46, pp. 221-233.

Hornsby J. S, Naffziger D. W, Kuratko D. F, Montagno R. V. (1993), An interactive model of the corporate entrepreneurship process. Entrepreneurship, Theory \& Practice, 17(2), pp. 29-37.

Lerner, M; Shaker, Z; Kohavi, Y.G, (2007), Time and corporate entrepreneurship: firm emergence and personality in the adaption of innovations, Research policy, Vol. 37, pp. 1550-1579.

Liao Chechen, Shu-Hui Chuang, Pui-Lai To (2010), How knowledge management mediates the relationship between environment and organizational structure, European management journal. 
Lumpkin, G.T. and Dess, G.G. (1996), Clarifying the entrepreneurial orientation construct and linking it to performance, Academy of Management Review, Vol. 21, No. 1, pp. 135-72.

Lumpkin, G. T; Cogliser, C. C; Schneider D, R.(2010), Understanding \& Measuring Autonomy: An Entrepreneurial Orientation perspective, Entrepreneurship: Theory and Practice, Vol. 33, pp. 47-69.

March, J. and Simon, H. (2009), Organizations, Blackwell, Cambridge, MA, pp. 195-324.

Mihm, J; Loch, Ch; Wilkinson, D; Huberman, B.A. (2010), Hierarchical structure and search in complex organizations, Management science, Vol. 56, No. 5, pp. 831-848.

Miller, D. (1983), Entrepreneurship correlates in three types of firms, Management Science, Vol. 29, pp. 770-791.

Morton A.N; Hu, Q. (2008), Implications of the fit between organizational structure and ERP: A structural contingency theory perspective, International Journal of Information Management, Vol. 28, pp. 391-402.

Naldi, L., Nordqvist, M., Sjoberg, K. and Wiklund, J. (2007), Entrepreneurial orientation, risk, pp. 997-1017.

Nunnally, J. C. (1978), Psychometric Theory (2nd ed.), McGraw-Hill, New York.

Robbins, S. P. (1998), Organization theory, New York, Prentice hall.

Robinson, R. B. (2007), Creating a 21 st century entrepreneurial organization, Academy of entrepreneurship journal, Vol. 8, No 1, pp. 321-332.

Shepherd, D; Covin, G.F; Kuratko F.D. (2008), Project Failure from Corporate Entrepreneurship: Managing the Grief Process, Journal of Business Venturing, Vol. 24, No. 6, pp. 588-600.

Willem, A; Buelens, M. (2009), Knowledge sharing in inter-unit cooperative episodes: The impact of organizational structure dimensions, International Journal of Information Management, Vol. 29, pp. 151-160.

Yao, X; Wen, W; Ren, Z. (2009), Corporate entrepreneurship in the enterprise clusters environment - Influence of network resources and entrepreneurial orientation on firm performance, Front. Bus. Res. China, Vol. 3, No 4, pp. 566-582.

Zahra, S. A; Covin, J. G. (1995), Entrepreneurship - performance relationship: a longitudinal analysis, Journal of business venturing, Vol. 10, No. 10, pp. 43-58. 